\title{
Recent Epidemic-Like Anthrax Outbreaks in Italy: What Are the Probable Causes?*
}

\author{
Lucia Palazzo ${ }^{1}$, Esterina De Carlo ${ }^{2}$, Gianfranco Santagada ${ }^{1}$, Luigina Serrecchia ${ }^{1}$, \\ Angela Aceti $^{1}$, Achille Guarino ${ }^{2}$, Rosanna Adone ${ }^{3}$, Antonio Fasanella ${ }^{1 \#}$ \\ ${ }^{1}$ Istituto Zooprofilattico Sperimentale della Puglia e della Basilicata, Foggia, Italy \\ ${ }^{2}$ Istituto Zooprofilattico Sperimentale del Mezzogiorno, Napoli, Italy \\ ${ }^{3}$ ISS-Istituto Superiore di Sanità, Roma, Italy \\ Email: \#a.fasanella@izsfg.it
}

Received January 18, 2012; revised February 2, 2012; accepted February 29, 2012

\begin{abstract}
In Italy, in an area of about $50 \mathrm{~km}^{2}$ between Basilicata and Campania Southern regions, 28 outbreaks of anthrax occurred from August $28^{\text {th }}$ to September $27^{\text {th }}$ 2011. Different species were affected: laboratory tests confirmed anthrax in cattle, horses and sheep. The genetic analysis of strains isolated from infected animals indicated that outbreaks occurring in the two regions were not correlated. Intriguingly, the incidence was highly significant in horses compared to that of cattle and sheep or goats, which were prevalent species in the animal population. In addition, allinfected horses and many cattle developed a fatal, sub-acute form of anthrax, characterized by the presence of massive edema, usually absent in hyperacute forms. The characteristics of these outbreaks suggested a possible role of tabanids as vectors in the transmission of $B$. anthracis like-epidemic infection.
\end{abstract}

Keywords: Anthrax; Epidemic; Edema; Horses; Tabanids

\section{Introduction}

Anthrax is a non contagious infectious disease that primarily affects unvaccinated domestic and wild ruminants. In these animals the classical form of the disease is characterized by sporadic outbreaks, usually occurring in the summer, involving a very low number of animals developing an hyperacute form in which they die without showing any symptoms.

Rarely, however, anthrax occurs as epidemic-like disease, characterized by many out breaks involving a very limited area and a large number of animals. In Italy, where anthrax is hypo-enzootic, two major epidemic-like anthrax outbreaks were recorded. During the 2004 summer in Basilicata, a Southern region of Italy, over 41 days, 81 cattle died, as well as 15 sheep, 9 goats, 11 horses, and 8 deer. All the isolates belonged to the same genotype 3, cluster A1a [1-3]. From August $28^{\text {th }}$ to September $27^{\text {th }}$, 2011, 28 outbreaks of anthrax were recorded in an area of about $50 \mathrm{~km}^{2}$, between Basilicata and Campania Southern regions of Italy, $50 \mathrm{Km}$ far from the area in which outbreaks of 2004 occurred. Over sixty animals, belonging to different species, developed a sub-acute

\footnotetext{
${ }^{*}$ Conflict of interest: The authors declared no potential conflicts of interest with respect to the research, authorship, and/or publication of this article.

${ }^{\#}$ Corresponding author.
}

form of anthrax and died. B. anthracis was isolated from 28 infected animals. The highest incidence of infection was recorded in horses, which also showed atypical clinical signs probably referred to anthrax infection acquired through the skin. In this study, the possible role of tabanids as vectors of the infection is discussed.

\section{Case Report}

From August $28^{\text {th }}$ to September $27^{\text {th }}, 2011,28$ outbreaks of anthrax were recorded in an area of about $50 \mathrm{~km}^{2}$, between Basilicata and Campania Southern regions of Italy, $50 \mathrm{~km}$ far from the area in which outbreaks of 2004 occurred. Laboratory tests confirmed anthrax in 16 cattle, 7 horses and 5 sheep. In detail, 6 cattle, 1 horse and 1 sheep died in Campania, while 10 cattle, 6 horses and 4 sheep died in Basilicata. The genetic analysis of strains isolated from infected animals indicated that outbreaks that occurred in the two regions were not correlated. In fact, two different B. anthracis genotypes were identified: strains isolated in Campania belonged to genotype GT/Sal, while all strains isolated in Basilicata belonged to genotype Gt/Pz1.

Moreover, an interesting aspect of these outbreaks was the high mortality rate recorded in horses and cattlein comparison with the lower involvement of sheep and goats, although they were prevalent species in the animal 
population. Compared to the estimated population in the territory, the highest incidence of infection was recorded in horses with $1.3 \%$ of the animals affected (7/551), followed by cattle with $0.16 \%(16 / 10.214)$ and sheep and goats with $0.03 \%(5 / 19.400)$. The incidence was highly significant in horses compared to that of cattle and sheep/goats $(P<0.001)$, and the incidence of cattle was significant respect to the incidence of sheep/goats $(P<$ 0.001). In addition, all the infected horses and many cattle developed a fatal sub-acute form, characterized by a huge swelling in different parts of their bodies.

\section{Discussion}

In these outbreaks, really interesting was the involvement of many horses given that horses in natural conditions are less receptive to anthrax than cattle, which usually contract the infection via food. Probably, since horses are monogastric, they are able to quickly neutralise the sporesingested with food by the acid chloride present in their stomach. On the contrary, horses seem to be more sensitive to anthrax infection acquired through the skin. In the past, in fact, when the Pasteur vaccines were used, whose administration was more difficult, vaccination accidents were more frequent in horses compared to ruminants [4]. These data bring us to consider that in the epidemic-like anthrax, the infection could be spread mainly by trancutaneous transmission. Recently, Blackburn et al. [5] isolated B. anthracis from flesh-eating flies and demonstrated the potential role in anthrax epizootics. Moreover, the hypothesis that blood-sucking insects such as tabanids (gadflies or horse-flies) can play an important roles in spreading diseases of livestock and other animals is widely accepted [6]. Generally, the gadflies suck the blood of large herbivores, such as horses and large ruminants, and their activity takes place in broad daylight on hot days and in the absence of wind, with the greatest intensity in middle and late summer. Typical of the female bloodsucking horseflies is the concentration of attacks on specific parts of the body, such as the head or lower limbs. Such behavior would be due to the mechanism of attraction based on color ocular perception. The gadfly's puncture is very painful so immediately gets the victim's attention, whose reaction can disrupt the insect's meal and force her to move to another point or to another animal. In general female tabanids are brief snackers and to complete a meal she will visit a number of animals over, a short period. This behavior facilitates the mechanical and accidental transmission of pathogens. The pathogen does not establish any biological relationship with the carrier. It merely takes a mechanical advantage of the fly's mouth parts to transfer infected host blood to a healthy host or hosts [6].

Finally, we wish to focus attention to the appearance of the clinical sign represented by the massive edema in different parts of the body given that this is absent in classical hyperacute forms. In anthrax experimental infections in rabbits, a massive subcutaneous edema is often observed around the inoculation site (personal data). Besides, recently, this clinical aspect has been highlighted in drug users, who died of injection anthrax following the use of anthrax-spore contaminated heroin. The description of clinical signs in 31 cases indicated that most of them presented an atypical, but severe, soft tissue infections, with significant soft-tissue edema [7]. Therefore edema seems a important clinical sign related to the injection infection of $B$. anthracis. On these data we can hypothesize that the epidemic-like anthrax is an evolution of the classic sporadic form, which follows upon the ingestion of contaminated soil while grazing loci with high spore concentrations, due to the actions of haemophagic flies. The tabanids feeding on this index case, usually a moribund animal and especially during the bacteraemic phase, are able to transfer the pathogen to nearby healthy animals in the same or neighbouring herds, causing the disease characterized by an extensive oedema due to an injection-source infection. This space multiplier effect has been described previously [8].

\section{Acknowledgements}

Thanks to Martin Hugh Jones and Michela De Candia for technical support.

\section{REFERENCES}

[1] A. Fasanella, L. Palazzo, A. Petrella, et al., "Anthrax in Reddeer (Cervuselaphus), Italy," Emerging Infectious Disease, Vol. 13, No. 7, 2007, pp. 1118-1119. doi:10.3201/eid1307.061465

[2] A. Fasanella, G. Garofolo, D. Galante, et al., "Severe Anthrax Outbreaks in Italy in 2004: Considerations on Factors Involved in the Spread of Infection,” New Microbiologica, Vol. 33, No. 1, 2010, pp. 83-86.

[3] G. Garofolo, A. Ciammaruconi, A. Fasanella, et al., "SNR Analysis: Molecular Investigation of an Anthrax Epidemic,” BMC Veterinary Research, 2010.

[4] P. Stazzi and A. Mirri, "Trattato di Malattie Infettive degli Animali Domestici,” Cisalpino Editore, IX Edition, 1954.

[5] J. K. Blackburn, A. Curtis, T. L. Hadfield, et al., "Confirmation of Bacillus anthracis from Flesh-Eating Flies Collected during a West Texas Anthrax Season,” Journal of Wildlife Diseases, Vol. 46, No. 3, 2010, pp. 918-922.

[6] W. L. Krinsky, “Animal Disease Agents Transmitted by Horse Flies and Deer Flies (Diptera: Tabanidae),” Journal of Medical Entomology, Vol. 13, No. 3, 1976, pp. 225275.

[7] M. G. Booth, J. Hood, T. J. Brooks and A. Hart, "Anthrax Infection in Drug Users,” Lancet, Vol. 375, No. 9723, 2010, pp. 1345-1346. 
doi:10.1016/S0140-6736(10)60573-9

[8] M. Hugh-Jones and J. Blackburn, “The Ecology of Bacillus anthracis,” Molecular Aspects of Medicine, Vol. 30,
No. 6, 2009, pp. 356-367.

doi:10.1016/j.mam.2009.08.003 